\title{
Cyclized polyacrylonitrile anode for alkali metal ion batteries
}

\author{
Wenli Zhang, ${ }^{[a]}$ Minglei Sun, ${ }^{[a]}$ Jian Yin, ${ }^{[a]}$ Edy Abou-Hamad,,${ }^{[b]}$ Udo Schwingenschlögl, ${ }^{[a]}$ Pedro M. F. J. \\ Costa, ${ }^{[a]}$ and Husam N. Alshareef*[a] \\ [a] Dr. W. Zhang, Dr. M. Sun, Dr. J. Yin, Prof. U. Schwingenschlögl, Prof. P. M. F. J. Costa, Prof. H. N. Alshareef \\ Materials Science and Engineering, Physical Science and Engineering Division, King Abdullah University of Science and Technology (KAUST), Thuwal \\ 23955-6900, Saudi Arabia \\ E-mail: husam.alshareef@kaust.edu.sa \\ [b] Dr. E. Abou-Hamad \\ Core labs, King Abdullah University of Science and Technology (KAUST), Thuwal 23955-6900, Saudi Arabia \\ Supporting information for this article is given via a link at the end of the document.
}

\begin{abstract}
Alkali metal ( $\mathrm{Li}, \mathrm{Na}$, and $\mathrm{K}$ ) ion batteries are vital in portable and large-scale stationary energy storage. Recently, organic anodes have attracted increasing attention for alkali metal ion batteries due to their chemical diversity and potential high capacity. In this work, we discovered that cyclized polyacrylonitrile (CPAN) can serve as a superior anode for alkali metal ion batteries. Remarkably, upon activation cycling, as an anode of lithium-ion battery, cPAN exhibits a reversible capacity as high as $1238 \mathrm{mAh} \mathrm{g}^{-1}$ under a current density of $50 \mathrm{~mA} \mathrm{~g}^{-1}$. Based on electrochemical experiments and firstprinciples calculations, it is demonstrated that the hexagonal carbon ring, piperidine ring, and pyridine nitrogen in ladder $C P A N$ are the main active sites for lithium-ion storage. In addition, we show that CPAN displays a unique potential-dependent solid electrolyte interphase formation from 0.1 to $0.01 \mathrm{~V}$ vs. $\mathrm{Li} / \mathrm{Li}^{+}$. Furthermore, $\mathrm{CPAN}$ displays decent performances as an anodes in SIBs and PIBs. The discovery of $C P A N$ anode could pave the way for the future development of organic anodes for alkali metal ion batteries.
\end{abstract}

\section{Introduction}

The increasing demand for extended-mileage electric vehicles has triggered intensive research activities on high capacity anode materials. ${ }^{[1-3]}$ Due to the scarcity of lithium resources, sodium-ion batteries (SIBs) and potassium ion batteries (PIBs) are being developed as low-cost alternatives for lithium-ion batteries (LIBs) in future large-scale stationary energy storage. ${ }^{[4-6]}$ High-capacity alloying anodes have been widely investigated to promote the energy density of alkali metal ion batteries. The main technological barrier for the commercialization of alloying anodes has been their poor stability during cycling, resulting from their high volume change and pulverization..$^{[7,8]}$ Various alloying and carbonaceous anodes have been investigated and implemented in commercial applications. ${ }^{[9,10]}$ Recently, organic compounds have attracted increasing attention for the anodes of alkali metal ion batteries.

Organic anodes have the merits of low energy consumption, tunable structures, chemical diversity, and little environmental impact after disposal. ${ }^{[11]}$ Most importantly, organic anodes could achieve a lithium-storage capacity higher than graphite. Polyacetylene, with a practical capacity of $340 \mathrm{mAh} \mathrm{g}^{-1}$, has been investigated as an anode in the early development of LIB. ${ }^{[12,13]}$ Various organic anodes, such as simple organic compounds (maleic acid, ${ }^{[14]}$ conjugated dicarboxylate, ${ }^{[15]} \pi$-conjugated triquinoxalinylene ${ }^{[16]}$ ), $\quad$ polymers $\quad$ (polyimides, ${ }^{[17]}$ poly(chalcogenoviologen), ${ }^{[18]}$ hexaazatriphenylene-based polymer ${ }^{[19]}$ benzophenolne-3,3',4,4'-tetracarboxylimide oligomer $(\mathrm{BTO})^{[20]}$ and polymeric Schiff bases ${ }^{[21]}$ ), and covalent organic frameworks (COF) (graphdiyne, ${ }^{[22,23]}$ triazine-based, ${ }^{[24]}$ triazoletriformyl phloroglucinol-based ${ }^{[25]}$ and other $\mathrm{COFs}^{[26,27]}$ ), have been investigated as the organic anodes of LIB. Nevertheless, organic anodes have been facing the issues of low capacity, poor cycling stability, dissolution in aprotic organic electrolytes, and low conductivity. The cycling stability of organic anodes could be improved by the formation of $\pi$ conjugated structures, ${ }^{[16]}$ while, the capacity of organic anode could be enhanced by the introduction of multi-functional active sites. ${ }^{[24]} \mathrm{New}$ organic anode family with abundant active sites and facile synthesis strategy is in urgent need to be explored and developed to support the fastgrowing LIB, SIB, and PIB technologies. ${ }^{[11]}$

Polyacrylonitrile (PAN) has been widely investigated and developed for the preparation of engineering carbon materials, ${ }^{[28]}$ and carbonaceous anodes for alkali metal ion batteries. ${ }^{[29,30]}$ The carbonaceous material prepared from annealing PAN at a temperature of $550{ }^{\circ} \mathrm{C}$ exhibited a moderate capacity of $550 \mathrm{mAh}$ $\mathrm{g}^{-1}$ as a LIB anode. ${ }^{[29]}$ Carbonaceous material derived from annealing PAN at $650^{\circ} \mathrm{C}$ delivered a capacity of around $230 \mathrm{mAh}$ $\mathrm{g}^{-1}$ for PIBs. ${ }^{[31]}$ Nevertheless, few research reported the energy storage capabilities of organic derivatives from PAN. Cyclized PAN (CPAN), with a partial $\pi$-electron system, has a ladder structure containing both $\mathrm{sp}^{3}$ hybridized $\mathrm{C}-\mathrm{C}(\mathrm{C}-\mathrm{N})$ bonds and $\mathrm{sp}^{2}$ hybridized $\mathrm{C}=\mathrm{C}(\mathrm{C}=\mathrm{N})$ bonds. ${ }^{[32,33]} \mathrm{CPAN}$ has been widely applied as an inert coating of electrode materials. ${ }^{[34,35]}$ However, cPAN has not been investigated as electrode active material. In this work, we demonstrate that $c P A N$, as a simple organic derivative of PAN, can be used as an anode in LIBs, SIBs, and PIBs. The hexagonal carbon ring, piperidine ring, and pyridine nitrogen are demonstrated as active sites for lithium-ion adsorption. This work opens a new avenue for alkali metal ion storage using cPAN based organic materials.

\section{Results and Discussion}

\section{Chemical structure of cPAN}

After exothermic condensing cyclization reaction at $280{ }^{\circ} \mathrm{C}$ shown by differential scanning calorimetry (DSC) (Figure 1a), linear PAN is transformed into laddered $C P A N$. CPAN shows brown color (Figure S1a) and block-shaped morphology as observed by scanning electron microscopy (SEM) image (Figure 
S2a). In stark contrast, PAN shows white color (Figure S1b) and sphere-shaped morphology (Figure S2b). High-resolution transmission electron microscopy (HRTEM) image of cPAN showed an amorphous structure with some parallel regions (Figure $1 \mathrm{~b}$ ) which are ascribed to the $\pi-\pi$ stacking of the ladder structures in CPAN. The defect-rich structure of $c P A N$ shown in HRTEM image (Figure 1c) indicates the low degree of crosslinking between ladder structures. The cyclization reaction of PAN completed as revealed by Fourier-transform infrared (FTIR) spectroscopy. PAN showed a typical peak at $2245 \mathrm{~cm}^{-1}$ (Figure S3), which is ascribed to the characteristic nitrile group ( $\mathrm{C} \equiv \mathrm{N}){ }^{\left[{ }^{[36]}\right.}$ After cyclization, this peak completely disappeared. Instead, a peak at $1596 \mathrm{~cm}^{-1}$ (Figure 1d) appeared, indicating the formation of $\mathrm{C}=\mathrm{N}$ or $\mathrm{C}=\mathrm{C}$ bonds in $c P A N$. The peak at $1257 \mathrm{~cm}^{-1}$ reflects the existence of $\mathrm{C}-\mathrm{N}$ single bonds in $C P A N$. The peak at $1376 \mathrm{~cm}^{-1}$ is due to the bending of $\mathrm{C}-\mathrm{H}$ bonds on the backbone of $\mathrm{CPAN}$. Minor methylene group $\left(\mathrm{CH}_{2}\right)$ existed due to the hydrogen radical reactions.
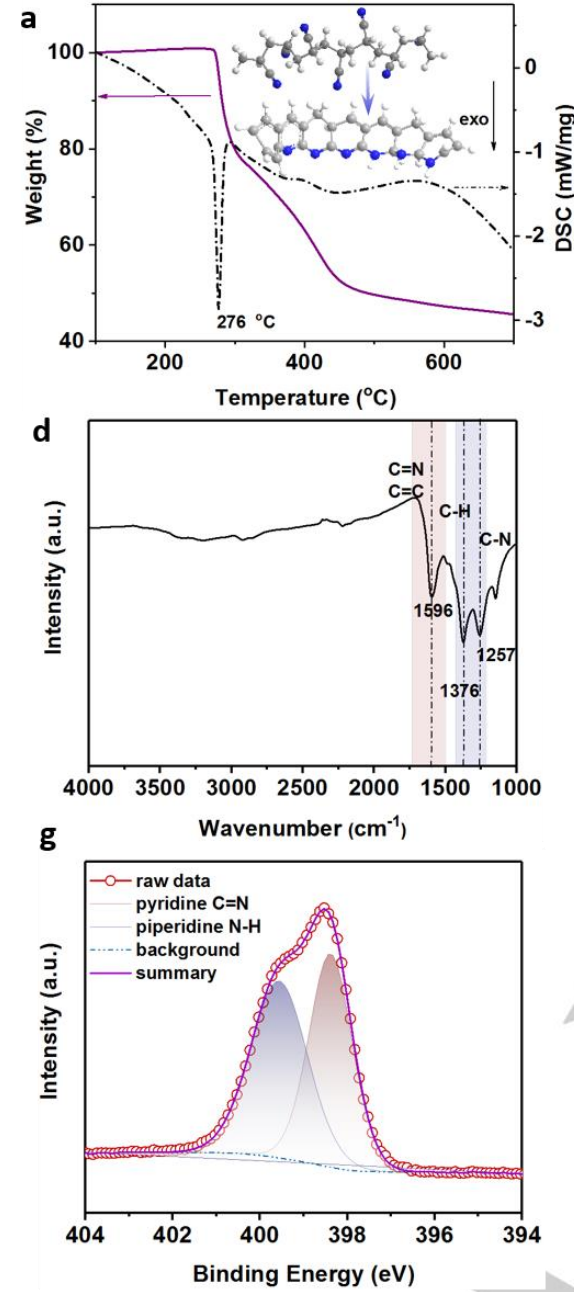
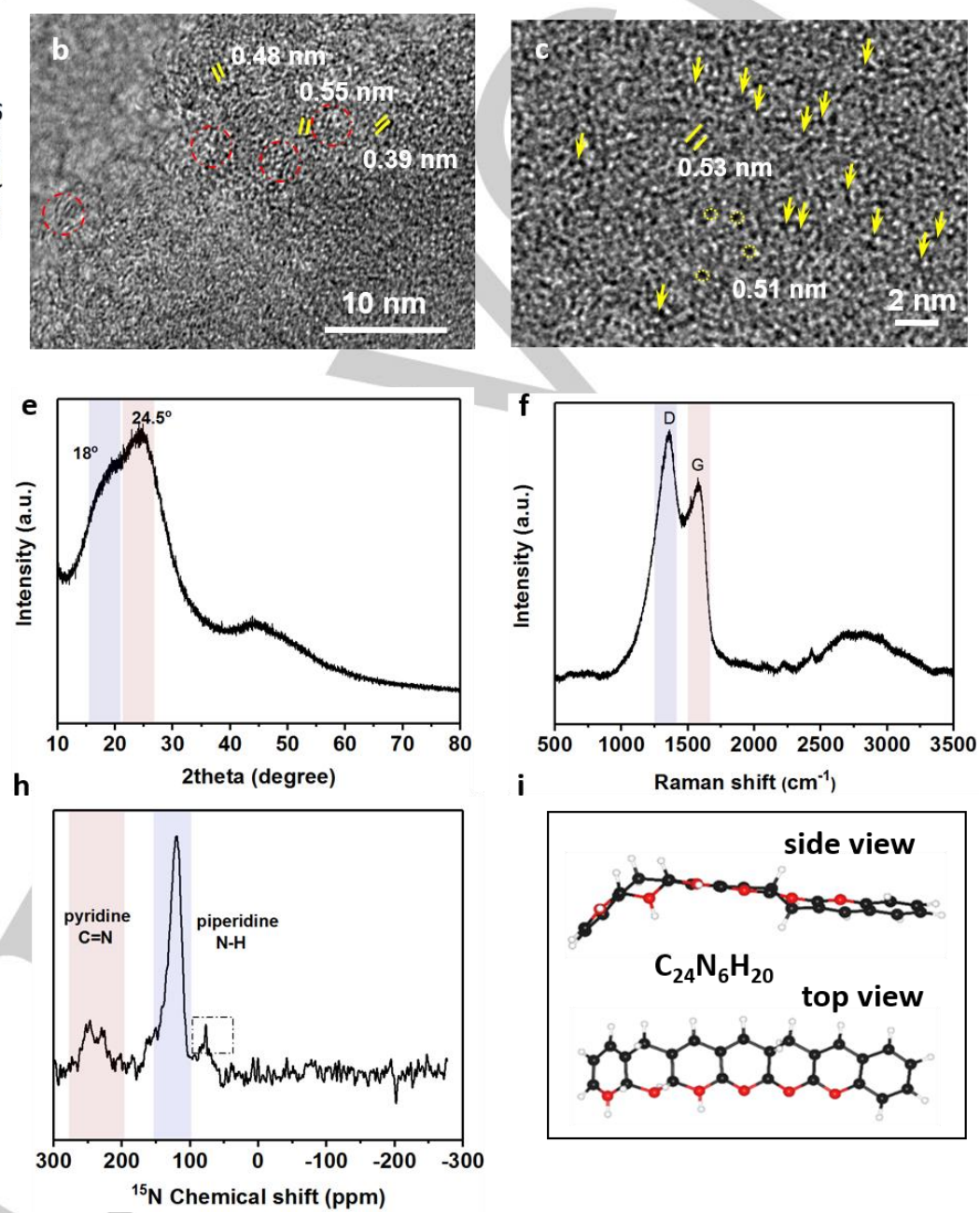

i

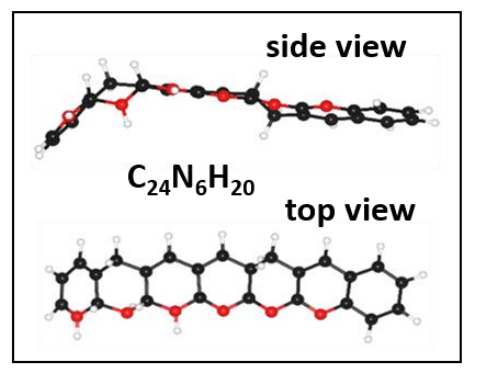

Figure 1 Physicochemical characterization of $C P A N$. (a) TGA and DSC curves of PAN. The inset schematic illustrates the cyclization of PAN. (b, c) HRTEM images of $c P A N$. The parallel yellow lines and red dashed cycles show the inter-ladder structure of $c P A N$, while the yellow arrows show the defective structure or isolated ladder structure. (d) FTIR spectra. (e) XRD pattern. (f) Raman spectra. (g) N 1s high-resolution XPS spectra. (h) ${ }^{15} \mathrm{~N}$ CP/MAS SS-NMR spectra. (i) Schematic diagram illustrating the structure of $c P A N$.

The semi-crystalline structure of PAN (Figure S4) evolved into amorphous carbon-like structure of $C P A N$. The XRD pattern of $c$ PAN had two broad peaks around $18^{\circ}$ and $24.5^{\circ}$ (Figure 1e), indicating large interlayer spacing between the neighboring ladder structure of $c$ PAN. The broad peak at $18^{\circ}$ demonstrates that the interlayer spacing of $c \mathrm{PAN}$ is much larger than amorphous carbon obtained by annealing PAN at $>500{ }^{\circ} \mathrm{C}$. ${ }^{[37]}$ Typical D $\left(1360 \mathrm{~cm}^{-1}\right)$ and $G\left(1570 \mathrm{~cm}^{-1}\right)$ peaks shown in Raman spectra indicate the co-existence of $\mathrm{sp}^{3}$ hybridized $\mathrm{C}-\mathrm{C}(\mathrm{C}-\mathrm{N})$ and $\mathrm{sp}^{2}$ hybridized $\mathrm{C}=\mathrm{C}$ $(\mathrm{C}=\mathrm{N})$ structures (Figure 1f). The precise chemical structure of cPAN was further interpreted by $\mathrm{X}$-ray photoelectron spectroscopy (XPS), solid-state nuclear magnetic resonance (SSNMR), and elemental analysis. After cyclization, the binding energy of $\mathrm{N} 1 \mathrm{~s}$ decreases from $401.5 \mathrm{eV}$ of the nitrile group (Figure S5) to $399 \mathrm{eV}$, which reveals the evolution of the chemical environment of nitrogen. The N 1s high-resolution XPS spectra of cPAN was deconvoluted into two major peaks centering at 398 and $399.5 \mathrm{eV}$ (Figure 1g). The peak at $398 \mathrm{eV}$ is attributed to the formation of pyridine nitrogen. The peak around $400 \mathrm{eV}$ is generally the pyrrolic nitrogen ${ }^{[38]}$ or piperidine nitrogen ${ }^{[39]}$ in carbonaceous materials, but is regarded as graphitic nitrogen in cPAN by some researchers. ${ }^{[34,35]}$ Since radical reactions of the scission of C-C bond mainly occur above $400^{\circ} \mathrm{C},{ }^{[40]}$ it is hard to 
have pyrrolic nitrogen in a pentagonal atom ring due to the low heat-treatment temperature of CPAN. So, it is necessary to differentiate the existence of piperidine or graphitic nitrogens in cPAN. To resolve this issue, we performed ${ }^{15} \mathrm{~N}$ CP/MAS SS-NMR. A broad peak ranging from 270 to $220 \mathrm{ppm}$ is attributed to the pyridine nitrogen in different hexagonal structures, while a peak with a chemical shift around $120 \mathrm{ppm}$ is the amine $(\mathrm{N}-\mathrm{H})$ bond from piperidine units (Figure $1 \mathrm{~h}$ ). A peak at $77 \mathrm{ppm}$ chemical shift is due to the formation of minor primary amines $\left(\mathrm{NH}_{2}\right)$. After cyclization, CPAN was not oxidized (Figure S6). The $1 \mathrm{D}^{1} \mathrm{H}$ MAS and $2 \mathrm{D}{ }^{1} \mathrm{H}-{ }^{15} \mathrm{~N}$ CP HETCOR SS-NMR (Figure S7) demonstrate the chemical environment of ladder CPAN and the formation of amine bonds. The formation of amine bonds is due to hydrogen transfer reactions (Figure S8).

The $\mathrm{C}$ 1s XPS spectra demonstrate the existence of $\mathrm{sp}^{2} \mathrm{C}=\mathrm{C}$, $\mathrm{sp}^{3} \mathrm{C}-\mathrm{C}, \mathrm{C}=\mathrm{N}$, and $\mathrm{C}-\mathrm{N}$ bonds in $\mathrm{CPAN}$ (Figure S9a), while the $\mathrm{O}$ 1s XPS spectra suggests the existence of minor oxygen in the form of ketone $(\mathrm{C}=\mathrm{O})$ (Figure $\mathrm{S} 9 \mathrm{~b})$. Finally, based on the elemental analysis, we proposed the chemical structure of $C P A N$ $\left(\mathrm{C}_{24} \mathrm{~N}_{6} \mathrm{H}_{20}\right.$ ) (Figure 1i). In the chemical structure of $c P A N$ (Figure 1i), $\mathrm{sp}^{3}$-hybridized $\mathrm{N}$ atom in piperidine provides one extra electron forming $\mathrm{N}-\mathrm{H}$ bond and an extra pair of $\mathrm{p}$-electrons. Pyridine nitrogen has one lone pair electrons forming $\mathrm{sp}^{2}$ hybridization and one single electron forming m-electron system. Both the piperidine and pyridine nitrogen could provide an electron-rich environment for adsorbing alkali metal ions. Energydispersive X-ray spectroscopy (EDS) and its mapping results confirmed the homogeneous distribution of carbon, nitrogen, and oxygen without phase separation (Figure S10). The narrow linewidth of electron paramagnetic resonance (EPR) (8 Gauss) compared with that of an amorphous carbon ${ }^{[41]}$ indicates the localized electrons and thus low cross-link degree among ladder cPAN structures (Figure S11).

\section{Electrochemical performances of cPAN}

The lithium-ion storage performance of CPAN was first investigated in Li//CPAN half-cell (Figure 2a) by cyclic voltammetry (CV) (Figure $2 b$ ). The $c P A N$ electrode with acetylene black $(A B)$ conductive agent showed lithium (de)intercalation peaks around $0.01 \mathrm{~V}$, and redox peaks around $0.95 \mathrm{~V}$ which could be caused by reversible redox reactions of $c P A N$. In the first cycle $\mathrm{CV}$, a broad cathodic peak ranging from 0.95 to $0.25 \mathrm{~V}$ appeared resulting from the formation of solid electrolyte interphase (SEI). CV curves recorded at various scan rates showed stable and reversible electrochemical behavior, indicating good rate capability (Figure S12). Based on the power-law relationship $\left(i=a v^{b},(0.5<b<1.0)\right)$ between current response $(i)$ and scan rate $(v)$, we calculated the $b$ value of the cathodic lithium intercalation process, a $b$ value of 1.2 higher than 1.0 was observed (Figure $\mathrm{S13a}$ ). The current response increases when either the cycle number or the scan rate increases. The abnormal $b$ value is attributed to the current (capacity) increase with a gradual increase of scan number (Figure S13b). Galvanostatic chargedischarge (GCD) was employed to investigate the lithium-ion storage performance of $C P A N$ (Figure 2c). Pure $C P A N$ without $A B$ additive showed a low discharge capacity of $31 \mathrm{mAh} \mathrm{g}^{-1}$ and a charge capacity of $19.3 \mathrm{mAh} \mathrm{g}^{-1}$ (Figure S14) due to its low conductivity $\left(3.81 \times 10^{-8} \mathrm{~S} \mathrm{~cm}^{-1}\right)$. Low specific capacities of pure organic anodes are usually observed in low-conductivity COF materials. ${ }^{[24,26]}$
To fully exert the lithium-ion storage capacity of $c P A N, c P A N$ was mechanically mixed with $A B$ and sodium carboxymethyl cellulose (CMC) binder to form a composite electrode. The CPAN electrode with $A B$ additive showed a first cycle discharge capacity of as high as $1210 \mathrm{mAh} \mathrm{g}^{-1}$ and a reversible charge capacity of $673 \mathrm{mAh} \mathrm{g}^{-1}$ (Figure 2c). The first GCD cycle showed a long tail approaching $0.01 \mathrm{~V}$. The zoom-in of this low potential range displayed an obvious oscillation phenomenon (Figure S15), which indicates that the lithiation occurs in two phases with $\mathrm{Li}^{+}$ concentration gradient. ${ }^{[42-44]}$ This may be resulted from the gradient lithium concentration in CPAN composite electrode, or the difference of lithium concentration in $A B$ and $C P A N$. We further tested the GCD curves at different current densities ranging from 50 to $5000 \mathrm{~mA} \mathrm{~g}^{-1}$ (Figure S16). After the rate test for 70 cycles, from the $71^{\text {st }}$ to $100^{\text {th }}$ cycles, the current density was switched back to $50 \mathrm{~mA} \mathrm{~g}^{-1}$, at the $100^{\text {th }}$ cycle, cPAN electrode showed higher capacity and lower polarization than the initial cycles at 50 $\mathrm{mA} \mathrm{g}^{-1}$ (Figure 2d). The initial Coulombic efficiency (ICE) of cPAN electrode was $55.6 \%$. The Coulombic efficiency (CE) quickly increased from $55.6 \%$ to $93.9 \%$, and to $98.0 \%$ from the first to the second and third cycle. The CEs retained high values around $99.5 \%$ afterward (Figure 2d). The capacities were tested stepwise at various current densities. The $c P A N$ electrode displayed capacities of $551,494,444,382,328,281,213 \mathrm{mAh} \mathrm{g}^{-1}$ at current densities of 50,100, 200,500, 1000, 2000, and $5000 \mathrm{~mA} \mathrm{~g}^{-1}$. When the current density was switched back to $50 \mathrm{~mA} \mathrm{~g}^{-1}, \mathrm{cPAN}$ electrode displayed a capacity of $544 \mathrm{mAh} \mathrm{g}^{-1}$ at the $71^{\text {st }}$ cycle, while the capacity increased to $681 \mathrm{mAh} \mathrm{g}^{-1}$ at the $100^{\text {th }}$ cycle. The rate capability was then tested again with the same protocol in Figure 2d. During the second-set test (Figure 2e), the cPAN electrode showed reversible capacities of $702,659,607,535,475$, 407 and $316 \mathrm{mAh} \mathrm{g}^{-1}$ at current densities of 50, 100, 200, 500, 1000,2000 and $5000 \mathrm{~mA} \mathrm{~g}^{-1}$. When the current density was switched back to $50 \mathrm{mAg}^{-1}$, the capacity recovered to $677 \mathrm{mAh} \mathrm{g}$ 1 at the $71^{\text {st }}$ cycle and $791 \mathrm{mAh} \mathrm{g}^{-1}$ at the $207^{\text {th }}$ cycle. The gradually increased capacities could be ascribed to the activation of the CPAN electrode and the exposure of active sites for lithiumion intercalation.

We further tested the long-term cycling stability of CPAN electrode for LIB anode at $1 \mathrm{~A} \mathrm{~g}^{-1}$ (Figure 2f). The CPAN electrode showed increasing CEs from $91.8 \%$ to $99 \%$ in the initial 50 cycles' GCD test (highlighted area in Figure 2f). The lower CE in the initial 50 GCD cycles could be due to the continuous SEI formation in the low potential range during cycling. The CPAN electrode displayed an initial capacity of $216 \mathrm{mAh} \mathrm{g}^{-1}$ for the first cycle. The capacity of $c P A N$ electrode increased quickly from the first to the $220^{\text {th }}$ cycles $\left(585 \mathrm{mAh} \mathrm{g}^{-1}\right)$, and gradually increased afterward to the $1000^{\text {th }}$ cycles. From $980^{\text {th }}$ to $1090^{\text {th }}$ cycles, the capacity of cPAN electrode stabilized around $810 \mathrm{mAh} \mathrm{g}^{-1}$ (Figure $2 \mathrm{f}$ and Figure S17a). The $1000^{\text {th }}$ GCD curve showed a much lower polarization of $54 \mathrm{mV}$ compared with the higher polarization of 173 $\mathrm{mV}$ at the $1^{\text {st }}$ cycle (Figure S17b). The decreased polarization of cPAN is due to the enlarged electrochemical active surface area and the decreased charge transfer resistance. After 1000 cycles' GCD cycling, we further tested the capacity at a current density of $50 \mathrm{~mA} \mathrm{~g}^{-1}$. The $c$ PAN electrode showed a reversible capacity of $1238 \mathrm{mAh} \mathrm{g}^{-1}$ with a high CE of $99.3 \%$ (Figure S18). It needs to be noted here that the capacity of $A B$ additive $\left(220 \mathrm{mAh} \mathrm{g}^{-1}\right.$ at 50 $\mathrm{mA} \mathrm{g}{ }^{-1}$, Figure S19) has been excluded. This high capacity corresponds to a high lithium concentration in $\mathrm{Li}^{+}$-intercalated cPAN $\left(\mathrm{Li}_{18} \mathrm{C}_{24} \mathrm{~N}_{6} \mathrm{H}_{20}\right)$. 
a
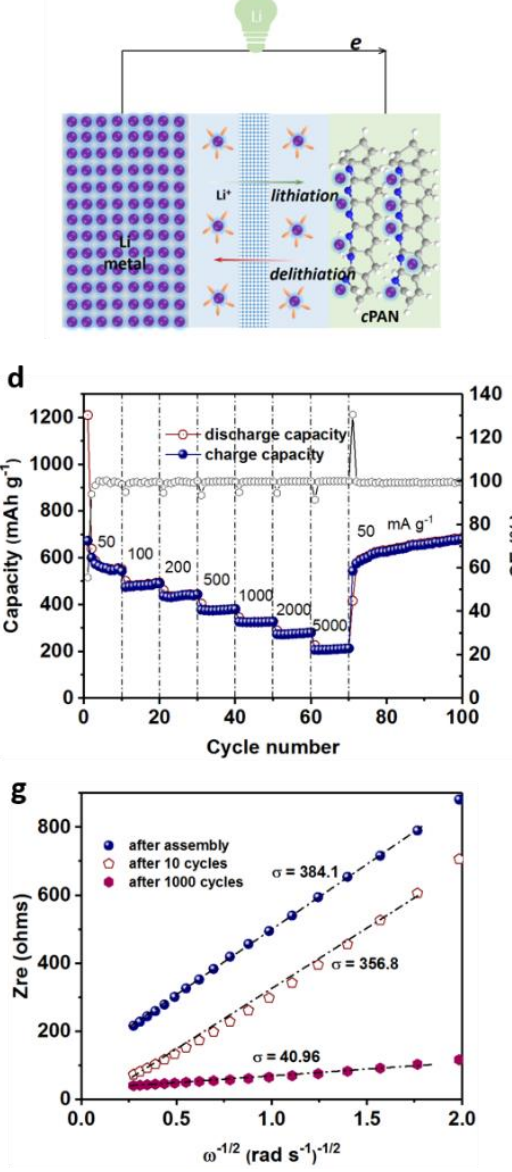

b
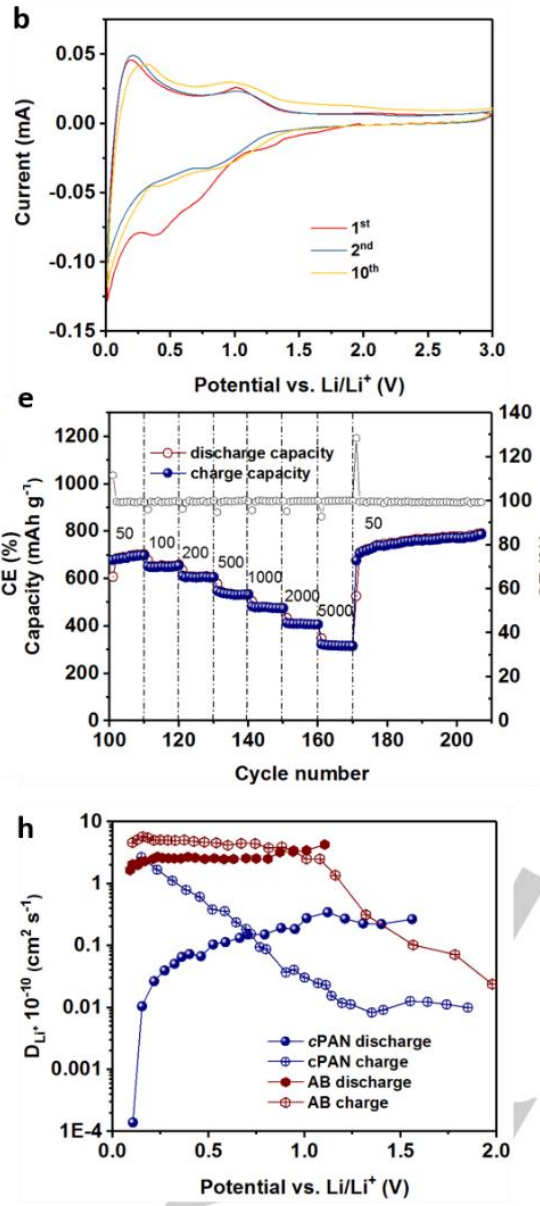
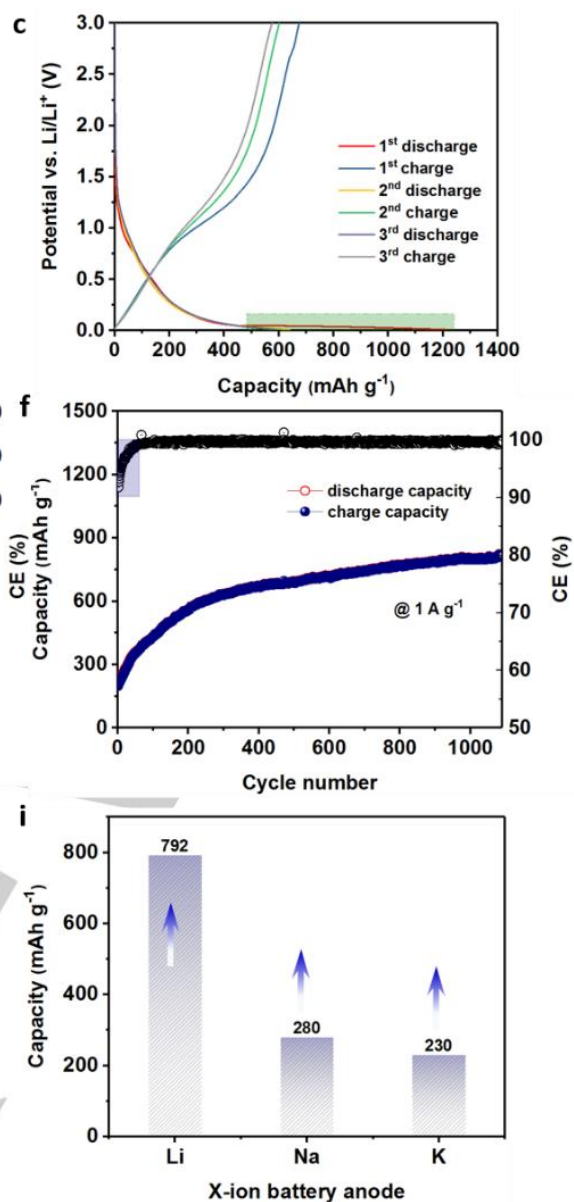

Figure 2 Electrochemical performances of $c P A N$ as LIB anode. (a) Schematic diagram of half-cell of $c P A N$. (b) CV curves of $c P A N$ electrode at a scan rate of $0.1 \mathrm{mV} \mathrm{s}^{-1}$. (c) The GCD curves of $c P A N$ at a current density of $50 \mathrm{~mA} \mathrm{~g}^{-1}$. (d, e) Rate capabilities of $c P A N$ at different current densities. (f) Dependence of capacities and CEs on cycle number at a current density of $1 \mathrm{~A} \mathrm{~g}^{-1}$. (g) Relationship between the real impedance with the reciprocal square root of the angular velocity. (h) Dependence of the diffusion coefficients of $A B$ and $c$ PAN on the potential. (i) Capacities of $c$ PAN for LIBs, SIBs, and PIBs.

We tracked the evolution of impedance by electrochemical impedance spectroscopy (EIS) during the GCD cycling process. The EIS spectra showed two semi-circles (resistances of SEI and charge transfer) at high-frequency range and an oblique line (semi-infinite diffusion-controlled process) at the low-frequency range. The $c P A N$ electrode showed decreased impedance upon cycling (Figure S20a and S20b), which is a sign that the charge transfer resistance decreases and the number of active sites increases. As the imaginary impedance decreased significantly with the increase of cycle number, we calculated the gravimetric capacitance at $10 \mathrm{mHz} \cdot{ }^{[45]} \mathrm{CPAN}$ had an initial gravimetric specific capacitance of $5.58 \mathrm{~F} \mathrm{~g}^{-1}$. After 10 cycles, the specific capacitance increased to $7.11 \mathrm{~F} \mathrm{~g}^{-1}$, and after 1000 cycles, the capacitance increased to $29.98 \mathrm{~F} \mathrm{~g}^{-1}$ (Figure S20c). The increased surface capacitance reveals the increase of electrochemically active sites for lithiation, which is in line with the decrease of charge transfer resistance. The increase of capacitance of $c P A N$ could be due to the exfoliation of CPAN during repeated GCD cycling, which effectively exposes the active sites. The exfoliation phenomenon of $c$ PAN after long-term cycling was observed by ex situ TEM (Figure S21). Further, we calculated the diffusion coefficient of $\mathrm{Li}^{+}$ ion based on the Warburg semi-infinite diffusion model using the low-frequency range of the EIS spectra. The Warburg coefficient $(\sigma)$ is calculated by the slope of $Z_{\mathrm{re}} v s \omega^{-1 / 2}$. The $\sigma$ values decreased from $384.1 \Omega \mathrm{s}^{-1 / 2}$ to $356.8 \Omega \mathrm{s}^{-1 / 2}$ to finally $40.96 \Omega \mathrm{s}^{-}$ $1 / 2$, from the $1^{\text {st }}$ cycle to the $10^{\text {th }}$ cycle and finally to the $1000^{\text {th }}$ cycle (Figure $2 \mathrm{~g}$ ). The diffusion coefficient of $\mathrm{Li}^{+}$ions $\left(\mathrm{D}_{\mathrm{Li}}^{+}\right)$increased from $1.03 \times 10^{-13} \mathrm{~cm}^{2} \mathrm{~s}^{-1}$ for the $1^{\text {st }}$ cycle, to the $1.19 \times 10^{-13} \mathrm{~cm}^{2} \mathrm{~s}$ ${ }^{1}$ for the $10^{\text {th }}$ cycle, and finally to $9.045 \times 10^{-12} \mathrm{~cm}^{2} \mathrm{~s}^{-1}$ for the $1000^{\text {th }}$ cycle (Figure S20d). The increased $\mathrm{D}_{\mathrm{Li}}{ }^{+}$suggests the enhanced diffusion pathways for $\mathrm{Li}^{+}$ions. We further performed galvanostatic intermittent titration technique (GITT) for the $C P A N$ to calculate $\mathrm{D}_{\mathrm{Li}}{ }^{+}$(Figure S22). Both $\mathrm{AB}$ and cPAN electrodes showed decreasing $\mathrm{D}_{\mathrm{Li}}{ }^{+}$in the lithiation process (Figure $2 \mathrm{~h}$ ). In the lithiation process at $0.5 \mathrm{~V}, \mathrm{CPAN}$ electrode had $\mathrm{a}_{\mathrm{Li}^{+}}{ }^{+}$of $6.7 \times 10^{-}$ ${ }^{12} \mathrm{~cm}^{2} \mathrm{~s}^{-1}$, while $A B$ had a $D_{\mathrm{Li}}{ }^{+}$of $2.6 \times 10^{-10} \mathrm{~cm}^{2} \mathrm{~s}^{-1}$ which is 38.8 times that of $c P A N$ electrode. The low $\mathrm{D}_{\mathrm{Li}^{+}}$of $C P A N$ may result from its hydrogen-rich skeleton. Furthermore, the $\mathrm{D}_{\mathrm{Li}}{ }^{+}$of $C P A N$ electrode showed a sharp decrease with deep lithiation to $0.01 \mathrm{~V}$, $\mathrm{D}_{\mathrm{Li}}{ }^{+}$decreased to a low value of $1.41 \times 10^{-14} \mathrm{~cm}^{2} \mathrm{~s}^{-1}$. The above results reflect the lower diffusion coefficient of $\mathrm{Li}^{+}$ions in $c P A N$ materials compared with carbonaceous $A B$ materials. Furthermore, we tested the $c \mathrm{PAN}$ as an anode for SIB and PIB. For SIB, cPAN anode showed a reversible electrochemical behavior, decent rate capability, and a stabilized capacity of 280 
mAh $\mathrm{g}^{-1}$ comparable to hard carbon anodes (Figure S23). ${ }^{[4]}$ As a $\mathrm{PIB}$ anode, cPAN also showed a reversible behavior, a decent stabilized capacity of $230 \mathrm{mAh} \mathrm{g}^{-1}$ (Figure 2i) and rate capability (Figure S24) comparable to graphitic carbon anodes. ${ }^{[46]}$ The reversible capacities of $c$ PAN as anodes for SIB and PIB are comparable to some anodes, such as graphitic carbon, ${ }^{[46]} 2 \mathrm{D}$ COF materials, ${ }^{[47]}$ and disodium terephthalates. ${ }^{[48,49]}$

\section{Electrode/electrolyte interface of cPAN electrode}

We performed ex situ XPS, SEM and TEM to track the evolution of the electrode/electrolyte interface. Pristine cPAN electrode showed comparable $\mathrm{N}$ 1s peak intensity compared with cPAN discharged to $0.2 \mathrm{~V}$ (Figure $3 \mathrm{a}$ ). The $\mathrm{N}$ 1s peak decreased as $c P A N$ was discharged from 0.2 to $0.1 \mathrm{~V}$. The $\mathrm{N}$ 1s peak intensity decreased sharply from $0.1 \mathrm{~V}$ to $0.01 \mathrm{~V}$ (Figure 3a), which indicates that the SEI on CPAN mainly forms in the potential range from 0.1 to $0.01 \mathrm{~V}$ which is much lower than most inorganic anodes (around 0.6-1.2 V vs. Li/Li+). ${ }^{[30,41,50-53]}$ The intensity of $\mathrm{N}$ 1 s peak did not recover when cPAN electrode was charged to 3.0 $\mathrm{V}$, which indicates that a robust SEI covers on CPAN. After discharged to $0.2 \mathrm{~V}$, the carbon content decreased from 79.4 at. $\%$ to 29.7 at. $\%$, while the carbon content stabilized around 24.0 at. \% after discharged to $0.1 \mathrm{~V}$ and $0.01 \mathrm{~V}$ (Figure $3 \mathrm{~b}$ ). The decreased carbon content of $c P A N$ electrode indicates that the SEI film is oxygen-rich. The oxygen content continued to increase from 0.2 to $0.01 \mathrm{~V}$, which suggests the continuous formation of $\mathrm{SEI}$. The oxygen content remained unchanged after $c P A N$ is charged to $3 \mathrm{~V}$, which indicates the stable chemical composition of SEI on CPAN electrode. Since the SEI forms on carbonaceous materials at a potential around $0.7 \mathrm{~V} \mathrm{vs}$. $\mathrm{Li}^{2} \mathrm{Li}^{+}$, we speculate that the SEI preferentially forms on $A B$ at $0.7 \mathrm{~V}$, and then the SEI forms on cPAN continuously from 0.1 to $0.01 \mathrm{~V}$. The lithiation and continuous SEI formation on CPAN could be the origin of the oscillation phenomenon at low potential.
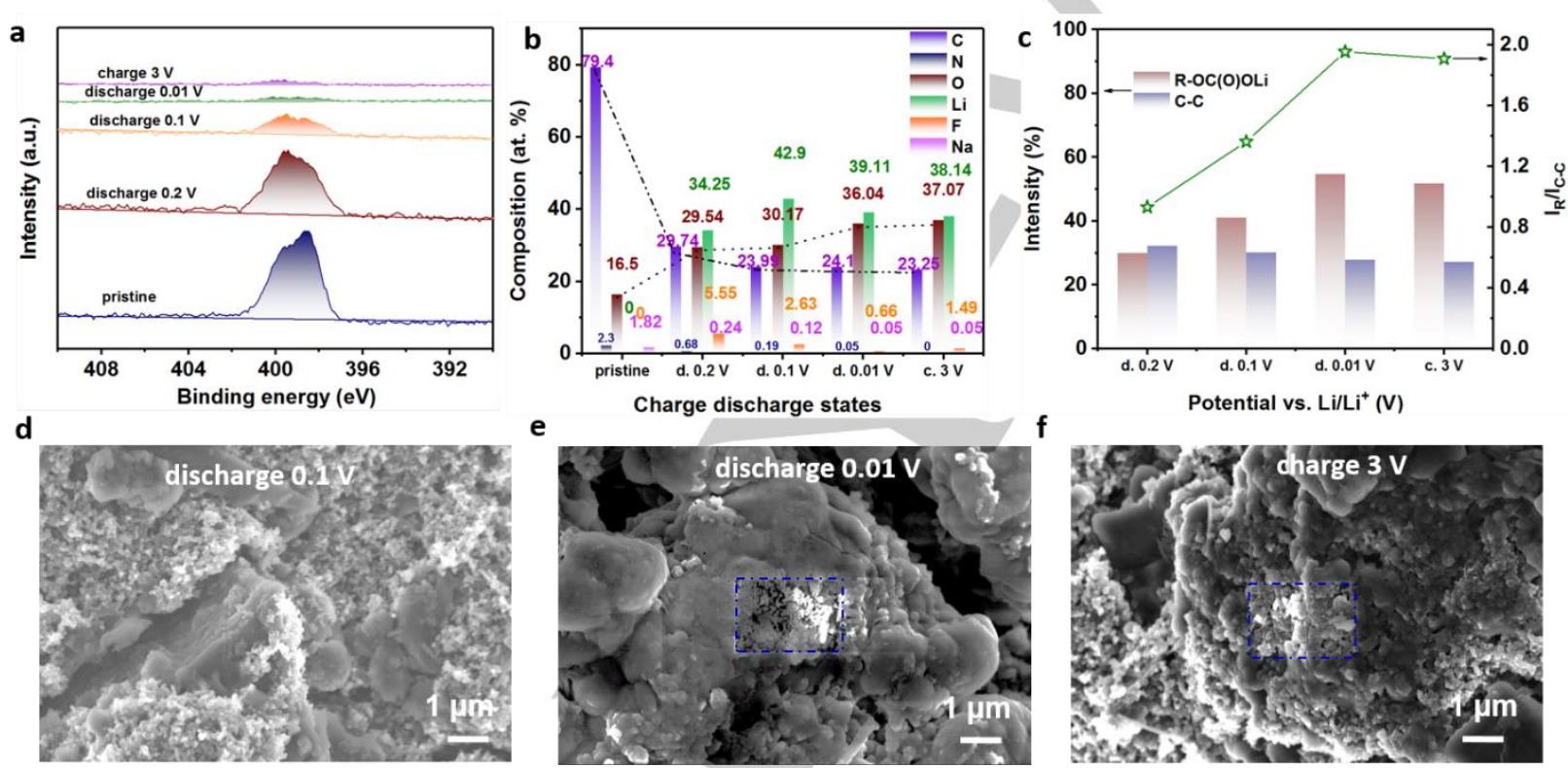

Figure 3 Evolution of surface chemistry of $c P A N$ electrode. (a) Evolution of N 1s XPS spectra. (b) Evolution of chemical compositions of $c$ PAN electrodes. (c) Relative intensities and their ratios of $\mathrm{R}-\mathrm{OCO}_{2} \mathrm{Li}$ and $\mathrm{C}-\mathrm{C}$. SEM images of $c P A N$ electrode (d) discharged to $0.1 \mathrm{~V}$, (e) discharged to $0.01 \mathrm{~V}$, and $(\mathrm{f})$ charged to $3 \mathrm{~V}$. The rectangular shape with blue dashed line shows the area exposed to the electron beam for $20 \mathrm{~s}$.

In XPS spectra, pristine cPAN electrode did not show a typical peak of lithium alkyl carbonates $\left(\mathrm{R}-\mathrm{CH}_{2}-\mathrm{OCO}_{2} \mathrm{Li}\right)$ in $\mathrm{SEI}$ (Figure S25). When CPAN was discharged to $0.2 \mathrm{~V}$, the appearance of $\mathrm{R}-\mathrm{CH}_{2}-\mathrm{OCO}_{2} \mathrm{Li}$ peak is related to the SEI formation on $\mathrm{AB}$. Since $\mathrm{R}-\mathrm{CH}_{2}-\mathrm{OCO}_{2} \mathrm{Li}$ is a typical component of $\mathrm{SEl},{ }^{[54-57]}$ we investigated the peak intensities of $\mathrm{R}-\mathrm{CH}_{2}-\mathrm{OCO}_{2} \mathrm{Li}$ and $\mathrm{C}-\mathrm{C}$ (Figure S26) to study the characteristic of SEI on CPAN electrode. We calculated the ratio of $\mathrm{R}-\mathrm{CH}_{2}-\mathrm{OCO}_{2} \mathrm{Li}$ to $\mathrm{C}-\mathrm{C}\left(I_{\mathrm{R}} / \mathrm{I}_{\mathrm{C}}\right)$ (Figure $3 c$ ). The intensity of $I_{R} / I_{C}$ gradually increased, which indicates the build-up of a SEI layer on CPAN. When CPAN was discharged from 0.2 to 0.1 , to $0.01 \mathrm{~V}$, there was a sharp increase of $I_{\mathrm{R}} / I_{\mathrm{C}}$ from 0.93 to 1.36 to 1.95 , which is a signal of increased $\mathrm{R}$ $\mathrm{CH}_{2}-\mathrm{OCO}_{2} \mathrm{Li}$ component and the SEI formation on CPAN particle. The $I_{R} / I_{C}$ ratio remained at 1.91 when $C P A N$ was charged to 3.0 $\mathrm{V}$, which reveals that the SEI on $C P A N$ has a stable composition. The SEM and TEM images of CPAN electrode did not show obvious SEI formation on CPAN from $0.2 \mathrm{~V}$ (Figure S27) to $0.1 \mathrm{~V}$ (Figure 3d and Figure S28a). However, manifest SEI film formed on CPAN at $0.01 \mathrm{~V}$ (Figure S28b), as this film decomposed when we increased the electron beam exposure time to more than 20 seconds (Figure $3 e$ and $3 f$ ). The formation of SEI on $C P A N$ is a slow and gradual process. SEI forms on $A B$ preferentially, and then the SEI forms on CPAN apparently from 0.1 to $0.01 \mathrm{~V}$ (Figure $\mathrm{S} 29 \mathrm{a})$. The $\mathrm{Li}^{+}$ion conductive SEl coupled with $\mathrm{Li}^{+} /$electron conductive $A B$ could facilitate the lithiation of $c P A N$ (Figure S29b), which enhances the reversible capacity of $C P A N$. The outer SEI on CPAN is rich in oligomers derived from the decomposition of electrolyte, while the inner SEI is rich in lithium species (Figure S30). $\mathrm{Li}$ 1s and F 1s XPS spectra demonstrate that the SEI contains $\mathrm{LiF}$ and $\mathrm{R}-\mathrm{CH}_{2}-\mathrm{OCO}_{2} \mathrm{Li}$ species (Figure S31). CPAN 
exhibits a unique SEl formation behavior at the potential range from 0.1 to $0.01 \mathrm{~V}$.
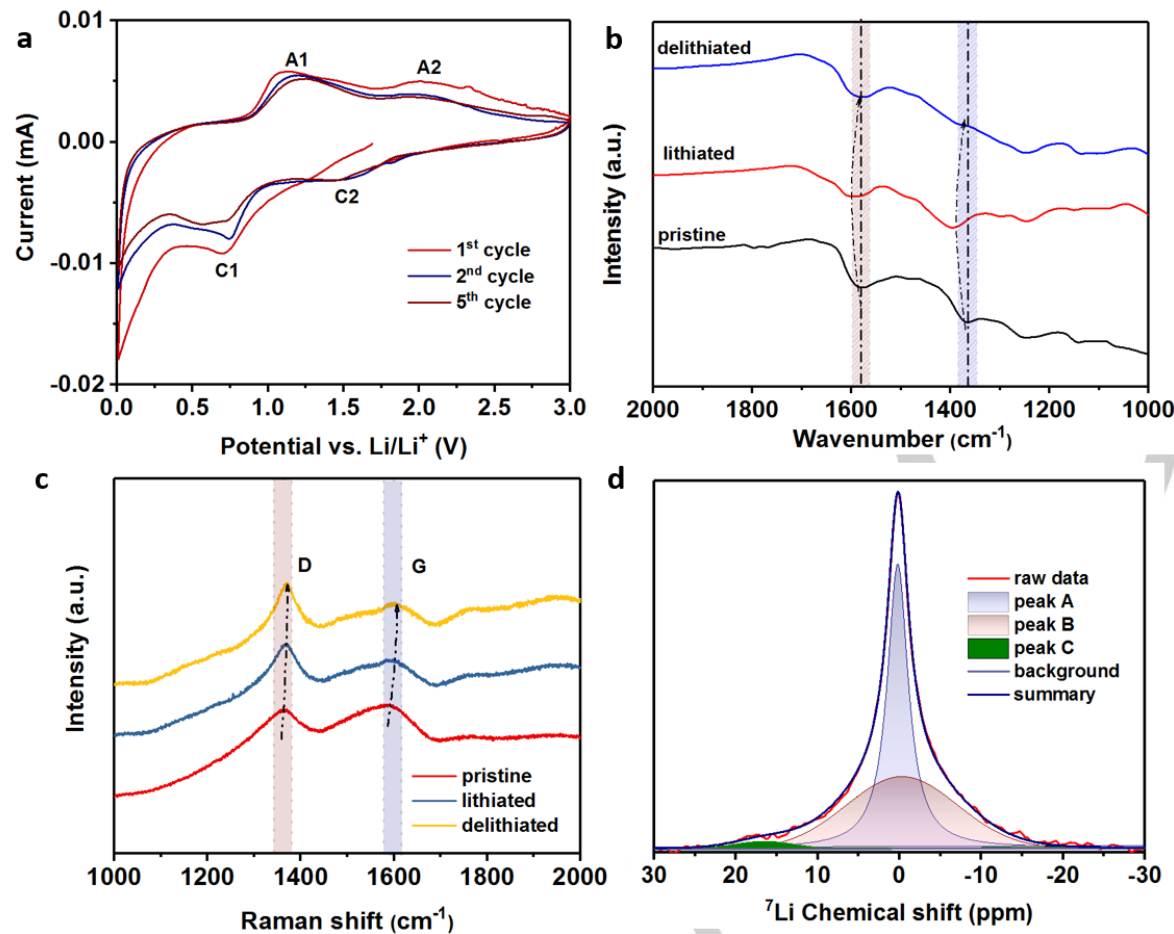

Figure 4 Mechanism of lithium-ion storage in $C P A N$. (a) CV curves of $C P A N$ electrode without $A B$ additive recorded at $0.05 \mathrm{mV} \mathrm{s}^{-1}$. (b) FTIR spectra of $c$ PAN. (c) Raman spectra of $c$ PAN electrode. (d) ${ }^{7}$ Li MAS SS-NMR spectra of $c$ PAN electrode discharged to $0.01 \mathrm{~V}$.

\section{The lithium storage mechanism of $c P A N$}

The lithium storage in CPAN was further studied by ex situ XRD, FTIR, Raman, and NMR. To show the (de)lithiation in pure CPAN material, we tested the $\mathrm{CV}$ of pure $C P A N$ electrode without $A B$ additives at $0.05 \mathrm{mV} \mathrm{s}^{-1}$. Besides the cathodic lithium intercalation peak around $0.01 \mathrm{~V}$, two pairs of redox peaks (A1, C1; A2, C2) appeared between 0.5 to $2.0 \mathrm{~V}$ (Figure 4a). These two pairs of redox peaks are attributed to electron transfer of CPAN, which is similar to a carbonaceous anode obtained by carbonizing PAN at $550^{\circ} \mathrm{C} .{ }^{[29]}$ We further tested the ex situ FTIR of $c P A N$ electrode. $c P A N$ showed a blue-shift of the $\mathrm{C}=\mathrm{N}$ peak from 1577 to $1592 \mathrm{~cm}^{-1}$ when fully lithiated. The position of $\mathrm{C}=\mathrm{N}$ peak recovered to $1581 \mathrm{~cm}^{-1}$ after cPAN was delithiated to $3.0 \mathrm{~V}$ (Figure $4 \mathrm{~b}$ ). The variation of wavenumber of $\mathrm{C}=\mathrm{N}$ peak is a direct evidence that pyridine nitrogen is involved in the (de)lithiation process, which is similar to pyridine nitrogen-doped amorphous carbon, ${ }^{[41]}$ and $\mathrm{C}=\mathrm{N}$ bonds in some organic polymers. ${ }^{[58]}$ The bending vibration of $\mathrm{C}-\mathrm{H}$ bond blue-shifted from $1365 \mathrm{~cm}^{-1}$ to 1396 $\mathrm{cm}^{-1}$ when $\mathrm{CPAN}$ was lithiated to $0.01 \mathrm{~V}$, while recovered to 1375 $\mathrm{cm}^{-1}$ when $C P A N$ was delithiated to $3.0 \mathrm{~V}$. The blue shift of peak of $\mathrm{C}-\mathrm{H}$ bond suggests the lithiation of the hexagonal atom rings, which is similar to the lithiation of hexagonal carbon rings in polyimides. ${ }^{[17]}$ Both the $D$ and $G$ peaks blue shifted due to the lithiation process (Figure 4c), which could be attributed to electron doping ${ }^{[59]}$ and the increase of the force constants of the in-plane C-C bonds. ${ }^{[60]}$ The peak position does not recover to its original position, which suggests that some lithium ions could be irreversibly adsorbed in the CPAN matrix. Ex situ XRD peak shifted to a higher $2 \theta$ value and then shifted back upon lithiation and delithiation (Figure S32), indicating reversible lithiation and delithiation behaviors of $c$ PAN. Ex situ ${ }^{7} \mathrm{Li}$ SS-NMR was used to probe the chemical environment of lithium species in lithiated cPAN (Figure 4d). The NMR spectra of lithiated cPAN was fitted into three components ( $A, B$ and $C$ ). Peak $A$ is ascribed to the lithium ions in ionic state from SEI or electrolyte residue. ${ }^{[61]}$ Peak $B$ is ascribed to the electrochemically adsorbed lithium ions in cPAN matrix. ${ }^{[37]}$ A small but visible peak $C$ at a chemical shift of $18 \mathrm{ppm}$ demonstrates the storage of $\mathrm{Li}^{+}$in adjacent ladder structures of $c P A N\left(L_{i} C_{x}\right)$. The above results demonstrate that $\mathrm{Li}$ ions are stored on the active sites of pyridine nitrogen, hexagonal atom ring in lithiated $c P A N$.

\section{First-principles calculations}

Furthermore, we performed first-principles calculations to probe the active sites for $\mathrm{Li}$ storage and the associated charge reconstruction. First, we tested several possible adsorption sites by calculation of the adsorption energy, $E_{\mathrm{a}}=E_{\text {total }}-E_{\mathrm{CPAN}}-E_{\mathrm{L}}$, where $E_{\text {total }}, E_{c P a n}$, and $E_{\mathrm{Li}}$ are the total energies of Li-adsorbed cPAN, a cPAN molecule, and a $\mathrm{Li}$ atom. According to this definition, a more negative $E_{\mathrm{a}}$ denotes a more favorable site. We identified four stable sites for $\mathrm{Li}$ adsorption: Adsorption beside a pyridine nitrogen atom yielded the most negative $E_{\mathrm{a}}$ of $-2.40 \mathrm{eV}$ (Figure $5 \mathrm{a}$ ), adsorption above the center of a hexagonal piperidine ring was less favorable $\left(E_{\mathrm{a}}=-0.66 \mathrm{eV}\right.$, Figure S33a) than adsorption above the hexagonal carbon ring $\left(E_{\mathrm{a}}=-1.00 \mathrm{eV}\right.$, Figure $5 b$ ), and adsorption beside a piperidine nitrogen atom yielded the least negative $E_{\mathrm{a}}$ of $-0.40 \mathrm{eV}$ (Figure $5 \mathrm{c}$ ). Charge difference isosurfaces for $\mathrm{Li}$ adsorption on different sites of $C P A N$ showed electron transfer from $\mathrm{Li}$ to $\mathrm{CPAN}$ (Figure 5d-i). In 
particular, the pyridine nitrogen atom strongly attracted electrons from the $\mathrm{Li}$ atom (Figure $5 \mathrm{~d}, \mathrm{~g}$ ). The electron transfers calculated by Bader analysis ${ }^{[62]}$ were $0.79,0.85,0.80$, and $0.52|\mathrm{e}|$ for the hexagonal carbon ring, pyridine nitrogen atom, hexagonal piperidine ring, and piperidine nitrogen atom, respectively (Figure $5 \mathrm{~d}-\mathrm{i}$ and S33b-c), which reflects an ionic bond nature between the $\mathrm{Li}$ atom and $\mathrm{CPAN}$ skeleton. The fact that the pyridine nitrogen atom displays a much more negative $E_{\mathrm{a}}$ than the piperidine nitrogen atom, although they both possess one lone pair of electrons, can be understood as follows: The $\mathrm{sp}^{2}$ hybridization of the pyridine nitrogen atom results in formation of a $\pi$ electron systems with the neighboring carbon atoms (Figure S34), which enables efficient charge transfer during lithiation of $c P A N$. In the case of the $\mathrm{sp}^{3}$-hybridized piperidine nitrogen atom, $\mathrm{H}$ atom weakens the ionic bonding with the $\mathrm{Li}$ atom. When $18 \mathrm{Li}$ atoms were adsorbed on CPAN, we obtained a rather negative average $E_{\mathrm{a}}$ of $-1.25 \mathrm{eV}$ (Figure S35), which reflects high capacity of $c P A N$ as LIB anode. Therefore, the pyridine nitrogen atom, hexagonal piperidine ring, and hexagonal carbon ring are active sites for efficient Li storage. a

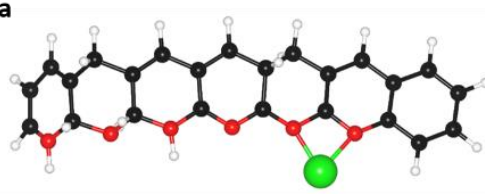

$E_{\mathrm{a}}=-2.40$

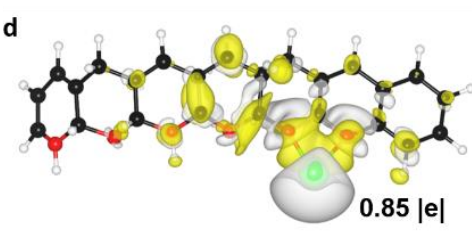

g

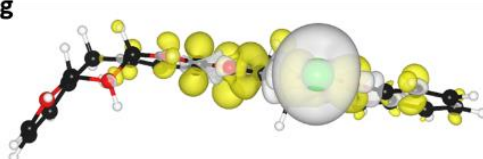

b

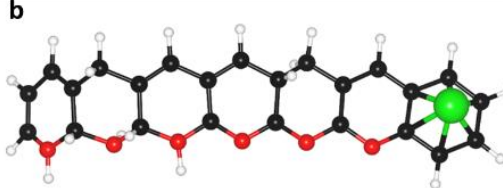

$E_{\mathrm{a}}=-1.00$

e

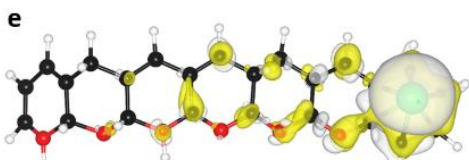

$0.79|\mathrm{e}|$

h

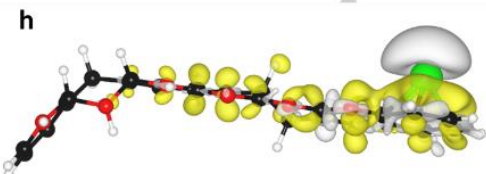

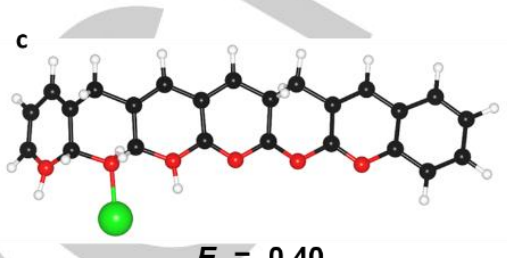

$E_{\mathrm{a}}=-0.40$

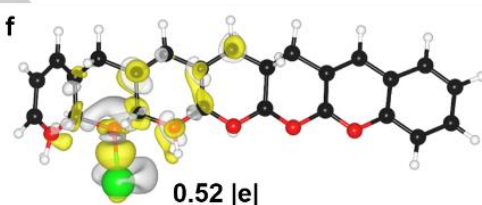

0.52 |e|

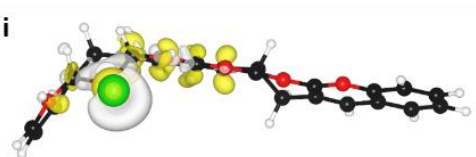

Figure 5 First-principles calculation results for Li adsorption on different sites of $c P A N$. (a-c) Optimized structures as well as (d-f) top and $(g-i)$ side views of the charge difference (isovalue $=0.01 \mathrm{e}^{\prime} \AA^{3}$ ) are shown for $\mathrm{Li}$ absorbed $(\mathrm{a}, \mathrm{d}$, and $\mathrm{g}$ ) beside a pyridine nitrogen atom, (b, e, and $\mathrm{f}$ ) above the center of the hexagonal carbon ring, and ( $c, f$, and i) beside a piperidine amine group. White, green, black, and red spheres denote $\mathrm{H}, \mathrm{Li}, \mathrm{C}$, and $\mathrm{N}$ atoms, respectively. Yellow and white isosurfaces denote accumulation and depletion of electrons, respectively. The amount of charge transfer obtained by Bader analysis and the adsorption energy are given.

\section{Conclusion}

In summary, we discovered that CPAN can be used as an anode in alkali metal-ion batteries. Experimental and computational studies demonstrate that $\mathrm{Li}^{+}$ions are reversibly adsorbed in cPAN matrix on the chemical structure of hexagonal carbon ring, piperidine ring, and pyridine nitrogen of the ladder cPAN formed in the cyclization process. After activation cycling, CPAN showed an ultrahigh capacity $1238 \mathrm{mAh} \mathrm{g}^{-1}$, which accounts for a theoretical formula of $\mathrm{Li}_{18} \mathrm{C}_{24} \mathrm{~N}_{6} \mathrm{H}_{20}$ with high lithium concentration. This high capacity outperforms the most wellstudied carbonaceous and organic anodes. Furthermore, cPAN could be used as an anode in SIBs and PIBs, in which CPAN showed decent capacity, rate capability, and cycling stability. The discovery of cPAN could pave the way to future development of organic anodes for alkali metal ion batteries.

\section{Acknowledgements}

The research reported in this publication is supported by King Abdullah University of Science and Technology (KAUST)
(URF/1/2980-01-01). The authors thank the Core Laboratories at KAUST for their excellent support.

Keywords: Lithium-ion battery $\cdot$ anode $\bullet$ polyacrylonitrile $•$ carbon $\cdot$ pyridine $\cdot$ active site

\section{Conflict of interest}

The authors declare no conflict of interest.

[1] J. Zheng, M. H. Engelhard, D. Mei, S. Jiao, B. J. Polzin, J. G. Zhang, W. Xu, Nat. Energy 2017, 2, 17012.

[2] Z. Tu, S. Choudhury, M. J. Zachman, S. Wei, K. Zhang, L. F. Kourkoutis, L. A. Archer, Nat. Energy 2018, 3, 310.

[3] X. Fan, L. Chen, O. Borodin, X. Ji, J. Chen, S. Hou, T. Deng, J. Zheng, C. Yang, S. C. Liou, K. Amine, K. Xu, C. Wang, Nat. Nanotechnol. 2018, 13, 715.

[4] W. Zhang, F. Zhang, F. Ming, H. N. Alshareef, EnergyChem 2019, 1, 100012.

[5] A. Bauer, J. Song, S. Vail, W. Pan, J. Barker, Y. Lu, Adv. Energy Mater. 2018, 8, 1702869.

[6] W. Zhang, Y. Liu, Z. Guo, Sci. Adv. 2019, 5, eaav7412.

[7] S. Choi, T. woo Kwon, A. Coskun, J. W. Choi, Science (80-. ). 2017, 357, 279.

[8] M. Ko, S. Chae, J. Ma, N. Kim, H. W. Lee, Y. Cui, J. Cho, Nat. Energy 2016, 1, 16113. 
[9] M. N. Obrovac, V. L. Chevrier, Chem. Rev. 2014, 114, 11444.

[10] P. Poizot, S. Laruelle, S. Grugeon, L. Dupont, J. Tarascon, Nature 2000, 407, 496.

[11] Y. Lu, J. Chen, Nat. Rev. Chem. 2020, 4, 127.

[12] L. W. Shacklette, J. E. Toth, N. S. Murthy, R. H. Baughman, J. Electrochem. Soc. 1984, 132, 1529.

[13] A. Yoshino, Angew. Chemie - Int. Ed. 2012, 51, 5798.

[14] Y. Wang, Y. Deng, Q. Qu, X. Zheng, J. Zhang, G. Liu, V. S. Battaglia, H. Zheng, ACS Energy Lett. 2017, 2, 2140.

[15] M. Armand, S. Grugeon, H. Vezin, S. Laruelle, P. Ribière, P. Poizot, J. M. Tarascon, Nat. Mater. 2009, 8, 120.

[16] C. Peng, G. H. Ning, J. Su, G. Zhong, W. Tang, B. Tian, C. Su, Di. Yu, L. Zu, J. Yang, M. F. Ng, Y. S. Hu, Y. Yang, M. Armand, K. P. Loh, Nat. Energy 2017, 2, 17074.

[17] H. Yang, S. Liu, L. Cao, S. Jiang, H. Hou, J. Mater. Chem. A 2018, 6, 21216.

[18] G. Li, B. Zhang, J. Wang, H. Zhao, W. Ma, L. Xu, W. Zhang, K. Zhou, Y. Du, G. He, Angew. Chemie - Int. Ed. 2019, 58, 8468.

[19] R. R. Kapaev, I. S. Zhidkov, E. Z. Kurmaev, K. J Stevenson, P. A. Troshin, J. Mater. Chem. A 2019, 7, 22596.

[20] Y. Wang, Z. Liu, H. Liu, H. Liu, B. Li, S. Guan, Small 2018, 14,1704094

[21] E. Castillo-Martínez, J. Carretero-González, M. Armand, Angew. Chemie - Int. Ed. 2014, 53, 5341.

[22] J. He, N. Wang, Z. Cui, H. Du, L. Fu, C. Huang, Z. Yang, X. Shen, Y. Yi, Z. Tu, Y. Li, Nat. Commun. 2017, 8, 1172.

[23] H. Shang, Z. Zuo, L. Li, F. Wang, H. Liu, Y. Li, Y. Li, Angew. Chemie - Int. Ed. 2018, 57, 774.

[24] Z. Lei, X. Chen, W. Sun, Y. Zhang, Y. Wang, Adv. Energy Mater. 2019, 9, 1801010.

[25] S. Haldar, K. Roy, S. Nandi, D. Chakraborty, D. Puthusseri, Y. Gawli, S. Ogale, R. Vaidhyanathan, Adv. Energy Mater. 2018, 8, 1702170.

[26] Z. Lei, Q. Yang, Y. Xu, S. Guo, W. Sun, H. Liu, L. P. Lv, Y. Zhang, Y. Wang, Nat. Commun. 2018, 9, 576.

[27] L. Bai, Q. Gao, Y. Zhao, J. Mater. Chem. A 2016, 4, 14106.

[28] T. Kyotani, N. Sonobe, A. Tomita, Nature 1988, 331, 331.

[29] B. Zhang, Y. Yu, Z. L. Xu, S. Abouali, M. Akbari, Y. B. He, F. Kang, J. K. Kim, Adv. Energy Mater. 2014, 4, 1301448.

[30] Y. Chen, Z. Lu, L. Zhou, Y.-W. Mai, H. Huang, Energy Environ. Sci. 2012, 5, 7898.

[31] X. Lin, J. Huang, B. Zhang, Carbon N. Y. 2019, 143, 138.

[32] Z. Liang, G. Zheng, C. Liu, N. Liu, W. Li, K. Yan, H. Yao, P. C. Hsu, S. Chu, Y. Cui, Nano Lett. 2015, 15, 2910.

[33] X. Liao, Y. Ding, L. Chen, W. Ye, J. Zhu, H. Fang, H. Hou, Chem. Commun. 2015, 51, 10127.

[34] D. M. Piper, T. A. Yersak, S. B. Son, S. C. Kim, C. S. Kang, K. H. Oh, C. Ban, A. C. Dillon, S. H. Lee, Adv. Energy Mater. 2013, 3, 697.

[35] S. B. Son, T. Gao, S. P. Harvey, K. X. Steirer, A. Stokes, A. Norman, C. Wang, A. Cresce, K. Xu, C. Ban, Nat. Chem. 2018, 10, 532.

[36] H. Zhang, L. Quan, F. Shi, C. Li, H. Liu, L. Xu, Polymers 2018, 10, 186.

[37] Y. Jung, M. C. Suh, H. Lee, M. Kim, S. I. Lee, S. C. Shim, J. Kwak, J. Electrochem. Soc. 1997, 144, 4279.

[38] W. Zhang, Z. Cao, W. Wang, E. Alhajji, A. H. Emwas, P. M. F. J. Costa, L. Cavallo, H. N. Alshareef, Angew. Chemie Int. Ed. 2020, 59, 4448.

[39] T. Takahagi, I. Shimada, M. Fukuhara, K. Morita, A. Ishitani, J. Polym. Sci. Part A Polym. Chem. 1986, 24, 3101.

[40] M. Jing, C. guo Wang, Q. Wang, Y. jun Bai, B. Zhu, Polym. Degrad. Stab. 2007, 92, 1737.

[41] W. Zhang, J. Yin, M. Sun, W. Wang, C. Chen, M. Altunkaya, A. H. Emwas, Y. Han, U. Schwingenschlögl, H. N. Alshareef, Adv. Mater. 2020, 32, 2000732.

[42] J. C. Gonzalez-Rosillo, M. Balaish, Z. D. Hood, N. Nadkarni, D. Fraggedakis, K. J. Kim, K. M. Mullin, R. Pfenninger, M. Z. Bazant, J. L. M. Rupp, Adv. Mater. 2020, 32, 1907465.
[43] T. R. Ferguson, M. Z. Bazant, Electrochim. Acta 2014, 146, 89.

[44] D. Li, Y. Sun, Z. Yang, L. Gu, Y. Chen, H. Zhou, Joule 2018, 2, 1265 .

[45] W. Zhang, Y. Lei, Q. Jiang, F. Ming, P. M. F. J. Costa, H. N. Alshareef, Small Methods 2019, 3, 1900005.

[46] W. Zhang, J. Ming, W. Zhao, X. Dong, M. N. Hedhili, P. M. F. J. Costa, H. N. Alshareef, Adv. Funct. Mater. 2019, 29, 1903641.

[47] H. Duan, P. Lyu, J. Liu, Y. Zhao, Y. Xu, ACS Nano 2019, 13, 2473.

[48] L. Zhao, J. Zhao, Y. S. Hu, H. Li, Z. Zhou, M. Armand, L. Chen, Adv. Energy Mater. 2012, 2, 962.

[49] Y. Park, D.-S. Shin, S. H. Woo, N. S. Choi, K. H. Shin, S. M. Oh, K. T. Lee, S. Y. Hong, Adv. Mater. 2012, 24, 3562.

[50] Y. Zhang, Q. Ma, S. Wang, X. Liu, L. Li, ACS Nano 2018 12, 4824.

[51] Z. L. Yu, S. Xin, Y. You, L. Yu, Y. Lin, D. W. Xu, C. Qiao, Z. H. Huang, N. Yang, S. H. Yu, J. B. Goodenough, J. Am. Chem. Soc. 2016, 138, 14915.

[52] B. Guo, X. Wang, P. F. Fulvio, M. Chi, S. M. Mahurin, X. G. Sun, S. Dai, Adv. Mater. 2011, 23, 4661.

[53] L. Qie, W. M. Chen, Z. H. Wang, Q. G. Shao, X. Li, L. X. Yuan, X. L. Hu, W. X. Zhang, Y. H. Huang, Adv. Mater. 2012, 24, 2047.

[54] Q. Shi, Y. Zhong, M. Wu, H. Wang, H. Wang, Proc. Natl. Acad. Sci. U. S. A. 2018, 115, 5676.

[55] S. Leroy, F. Blanchard, R. Dedryvère, H. Martinez, B. Carré, D. Lemordant, D. Gonbeau, Surf. Interface Anal. 2005, 37, 773.

[56] K. Ciosek Högström, S. Malmgren, M. Hahlin, M. Gorgoi, L. Nyholm, H. Rensmo, K. Edström, Electrochim. Acta 2014, $138,430$.

[57] B. Sun, C. Xu, J. Mindemark, T. Gustafsson, K. Edström, D. Brandell, J. Mater. Chem. A 2015, 3, 13994.

[58] Z. Man, P. Li, D. Zhou, R. Zang, S. Wang, P. Li, S. Liu, X Li, Y. Wu, X. Liang, G. Wang, J. Mater. Chem. A 2019, 7, 2368.

[59] E. Pollak, B. Geng, K. J. Jeon, I. T. Lucas, T. J. Richardson, F. Wang, R. Kostecki, Nano Lett. 2010, 10, 3386 .

[60] C. Sole, N. E. Drewett, L. J. Hardwick, Faraday Discuss. 2014, 172, 223.

[61] K. Sato, M. Noguchi, A. Demachi, N. Oki, M. Endo, Science 1994, 264, 556 .

[62] W. Tang, E. Sanville, G. Henkelman, J. Phys. Condens. Matter 2009, 21, 084204. 
WILEY-VCH

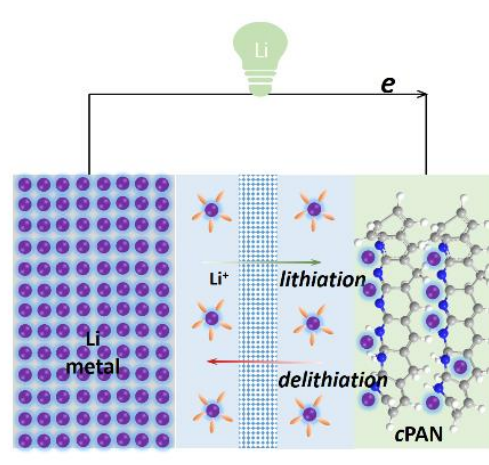

Emerging organic anode for alkali metal ion batteries: cyclized polyacrylonitrile is developed as an efficient anode material for alkali metal $(\mathrm{Li}, \mathrm{Na}$, and $\mathrm{K}$ ) ion batteries. This new organic anode exhibits high capacity and long cycle life. The discovery of cyclized polyacrylonitrile anode paves the way to new organic anodes for rechargeable batteries. 